Neurosci Lett. 2014 October 17; 582: 54-58. doi:10.1016/j.neulet.2014.08.040.

\title{
Disruption of Lateral Olivocochlear Neurons With a Dopaminergic Neurotoxin Depresses Spontaneous Auditory Nerve Activity
}

\author{
Colleen G. Le Prell ${ }^{a}$, David F. Dolan ${ }^{b}$, Larry F. Hughes ${ }^{c}$, Richard A. Altschuler ${ }^{b}$, Susan E. \\ Shore $^{\mathrm{b}}$, and Sanford C. Bledsoe Jr. ${ }^{\mathrm{b}}$ \\ aDepartment of Speech, Language, and Hearing Sciences, University of Florida, Gainesville, \\ 32610 USA
}

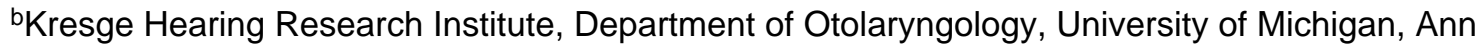
Arbor, 48109 USA

'Department of Surgery, Southern Illinois University Medical School, Springfield, 62794 USA

\begin{abstract}
Neurons of the lateral olivocochlear (LOC) system project from the auditory brainstem to the cochlea, where they synapse on radial dendrites of auditory nerve fibers. Selective LOC disruption depresses sound-evoked auditory nerve activity in the guinea pig, but enhances it in the mouse. Here, LOC disruption depressed spontaneous auditory nerve activity in the guinea pig. Recordings from single auditory nerve fibers revealed a significantly reduced proportion of fibers with the highest spontaneous firing rates (SRs) and an increased proportion of neurons with lower SRs. Ensemble activity, estimated using round window noise, also decreased after LOC disruption. Decreased spontaneous activity after LOC disruption may be a consequence of reduced tonic release of excitatory transmitters from the LOC terminals in guinea pigs.
\end{abstract}

\section{Keywords}

olivocochlear efferents; auditory nerve; spontaneous activity; MPTP; guinea pig

Type I auditory nerve (AN) fibers innervate cochlear inner hair cells (IHCs) [14, 42]. Fibers on the pillar side of the IHC have lower thresholds and higher spontaneous rates (SRs) than those on the modiolar side [23]. Pre-synaptic ribbon and post-synaptic receptor size may critically influence AN response properties, as synapses on the pillar side (lower threshold, higher SR) have smaller ribbons and larger receptor patches than those on the modiolar side (higher threshold, lower SR) [19]. The lateral olivocochlear (LOC) efferent system also influences AN response properties. LOC efferents originate in the lateral superior olive (LSO) and synapse primarily on radial dendrites of Type I AN fibers under the IHCs [22]. LOC innervation is biased towards the IHC modiolar side; there, low-SR fibers are innervated by twice as many LOC terminals as high-SR fibers [22]. In addition, a small

Corresponding author: C. G. Le Prell, Box 100174, Department of Speech, Language, and Hearing Sciences, University of Florida, Gainesville, FL, 32610, USA. Tel: +1-352-273-6163; fax +1-352-273-6545. colleeng@ phhp.ufl.edu. 
number of LOC neurons synapse directly on IHCs [21, 40, 41]. LOC efferents contain a variety of neurotransmitters, including dopamine (DA), dynorphin (dyn), enkepalin (enk), $\gamma$ aminobutyric acid (GABA), acetylcholine (ACh), and calcitonin-gene-related peptide (CGRP) [for reviews, see 1, 7, 12, 16, 18, 34]. There is significant transmitter colocalization, although the pattern varies across reports [4, 26, 36-38]. Taken together, LOC efferents are positioned to dynamically regulate AN fiber activity via differential release of excitatory and inhibitory neurotransmitters [for discussion, see 14]. Loss of LOC efferents results in greater noise-induced CAP amplitude decreases [14], a finding that is consistent with recent observations that low-SR fibers are more vulnerable to noise than high-SR fibers $[8,25]$.

Data from lesion [15, 17, 21, 48, 50], electrical stimulation [10], and gene knockout [27-30, 45] studies suggest several potential functional roles for LOC neurons. LOC modulation of AN activity may support interaural level comparisons necessary for accurate sound localization $[2,10]$, including relearning of localization tasks after unilateral conductive hearing loss [11]. LOC modulation of AN activity may be involved in the protective phenomenon termed "conditioning" [32,33]. We do not have a precise understanding of the role of LOC efferents in auditory function, however, as it is challenging to record from these small, unmyelinated neurons. Their close proximity to medial olivocochlear (MOC) efferents makes selective lesions difficult, and chemical diversity of LOC neurons further complicates systematic manipulation. Improved understanding of the role of LOC efferents in normal AN function, and their role in mediating AN vulnerability, is needed. Interestingly, recent mouse studies show decreased numbers of AN synapses after LSO damage [24], suggesting LOC neurons support AN survival and function.

Brainstem knife-cut studies provided some early insight; after cuts disrupting both MOC and LOC efferents, small but statistically significant AN threshold elevations have been consistently observed at some subset of test frequencies, in addition to decreased SRs [21, $48,50]$. Effects of MOC vs LOC disruption cannot be distinguished, however. Two approaches that selectively disrupt LOC efferents have since been used. First, small volumes of the cytolytic melittin can be injected into the LSO. Selective LSO damage depressed sound-driven AN activity in guinea pigs, measured as decreased whole-nerve compound action potential (CAP) amplitude [17]. With lesions largely centered in the lateral (lowfrequency) limb of the LSO, responses evoked by low-frequency sounds were the most suppressed. In contrast, lesions of the medial and lateral limb of mouse LSO resulted in 30-50\% increases in amplitude of wave I of the sound-evoked auditory brainstem response (ABR) [3]. A second method for disrupting LOC efferents is application of the DA neurotoxin 1-methyl-4-phenyl-1,2,3,6-tetrahydropyridine (MPTP) to the round window membrane (RWM) [15]. MPTP is metabolized to MPP+ and taken up pre-synaptically by neurons containing DA; accumulation of MPP+ results in mitochondrial dysfunction, oxidative stress, and neuronal death [31, 43]. Approximately $40 \%$ of the LOC innervation was disrupted 45-min after applying MPTP, and CAP amplitude reductions were equivalent to those measured after LSO lesions using melittin [15].

Across studies, the main effect of LOC lesions has been a change in sound-evoked auditory potential amplitude. In guinea pigs, CAP amplitude was depressed [15, 17]. The net effect 
differed in mice, with ABR wave I amplitude increasing post-lesion [3]. Although effect direction varied with species, it is clear that disrupting LOC integrity influenced soundevoked AN activity. Both CAP and ABR are indirect measures of AN activity; a change in response amplitude indicates a different number of AN fibers discharging synchronously. Decreased CAP amplitude in guinea pigs after LSO lesions may reflect a decrease in the number of AN fibers, or increased asynchronous activity, with fewer fibers responding synchronously to sound. This study specifically examined effects of selective LOC disruption via MPTP on spontaneous AN activity. If LOC transmitters are released tonically, then LOC disruption should alter spontaneous AN activity.

\section{Materials and methods}

\section{Subjects}

Subjects were 25 healthy, male and female adult pigmented guinea pigs (Elm Hill Breeding Labs, Chelmsford, MA) weighing 300-450 g. Animals were maintained with free access to food (Guinea Pig Chow, PMI Nutrition International Inc., Brentwood, MO) and water. The animal care program was AALAC accredited and husbandry met all applicable standards. All protocols were approved by the University Committee on Use and Care of Animals at the University of Michigan.

\section{Procedure Overview}

Animals were anesthetized [intramuscular ketamine $(40 \mathrm{mg} / \mathrm{kg})$ and xylazine $(10 \mathrm{mg} / \mathrm{kg})$ with supplemental anesthesia as needed]; rectal temperature was maintained at $38 \pm 0.5^{\circ} \mathrm{C}$ via thermostatically-controlled heating pad. Tympanic membranes were examined; then, the left bulla exposed and opened via post-auricular surgical approach. The cochlea was visualized and a silver ball electrode placed against the RWM. Electrodes were temporarily secured at the bulla using cyanoacrylate (VetBond), securely cemented to the bulla (Durelon), and then used to measure CAP.

\section{Whole-nerve sound-evoked CAP recordings}

CAP input-output (IO) functions were determined for brief pure-tone stimuli $(2-18 \mathrm{kHz}, 2$ kHz increments; 0-100 dB SPL in 5-dB increments; 5-ms duration, 0.5-ms rise-fall; 10/s). Stimuli were generated using Tucker-Davis Technology (TDT; Alachua, FL) System II/III hardware and SigGen 3.2 software. Signals were converted to analog (DA1), filtered (FT6-2, Fc $=40 \mathrm{kHz}$ ), attenuated (PA5), and presented using a 200-W transducer (Beyer Dynamic, Farmingdale, NY) coupled to the ear canal via the ear bars. Evoked potentials were filtered (300-3,000 Hz) and amplified (1,000X) using in-house constructed equipment. BioSig 3.2 was used to average 25 presentations within each frequency/level combination. IO functions were measured immediately after securing the electrode and 30-min after RW application of test substances (6- $\mu$ l volume); the middle ear was carefully dried prior to each CAP test using fine tip cotton points. In control subjects, an artificial perilymph (AP) solution was applied (145-mM NaCl, 2.7-mM KCl, 2.0-mM MgSO4, 1.2-mM CaCl2, 5.0$\mathrm{mM}$ HEPES; $\mathrm{pH}=7.40$, osmolality=280-285 mosM). In experimental subjects, 50-mM MPTP dissolved in AP was applied ( $\mathrm{pH}$ adjusted to 7.4 \pm 0.02 ). CAP threshold was defined using linear interpolation as the sound level that produced a $10-\mu \mathrm{V}$ response. 


\section{Round window noise (RWN) ensemble activity recordings}

In one subject, the RW electrode was used to record ensemble spontaneous AN activity [following 5, 39]. The recorded electrical noise was filtered $(0.3-3.0 \mathrm{kHz})$ and transmitted to a spectrum analyzer (SR760, Stanford Research Systems, Sunnyvale, CA; sampling rate $=256-\mathrm{kHz}$, frequency span $=0-12.5-\mathrm{kHz}, 32-\mathrm{msec}$ time-domain records). Fast Fourier transform (FFT) was performed on each record, using Blackman-Harris (BMH) windowing (frequency resolution of resulting $\mathrm{FFT}=31.25 \mathrm{-Hz}$ ). $150 \mathrm{FFTs}$ of records were acquired and averaged (linear, RMS averaging). In a normal animal, peak activity is around 900-Hz. A MATLAB $^{\mathrm{TM}}$ script was used to retrieve the waveform from the SR760 and store data.

\section{Auditory nerve single-unit recordings}

For single-unit recordings, a tracheal tube was inserted and subjects were held in a stereotaxic device (Kopf Model 1404) with hollow ear bars for sound delivery. A posterior fossa approach was used for AN fiber recordings $[6,35,46]$. In brief, the skin was incised and retracted, the bone over the cerebellum and posterior occipital cortex was removed, and a small portion of cerebellum aspirated to expose the AN. Spontaneous and sound-evoked potentials were recorded from AN fibers using glass micropipettes filled with $3-\mathrm{M} \mathrm{NaCl}$ (20-40 megohm impedances). A Plexon Inc. data-acquisition system operated in a singlechannel configuration was used to sample AN activity. Noise bursts (85-dB SPL, 50-msec duration, 10/sec) were used as search stimuli while advancing the micropipette through the nerve. SR was recorded for 30-sec from isolated AN fibers. Single units were identified by consistency of waveform shape and amplitude on a digital storage oscilloscope and confirmed by principal component analysis using RASPUTIN Sort Client (Plexon Inc).

\section{Results}

MPTP suppressed CAP amplitude 30-min post-application as previously described (Le Prell et al., 2005). Here, we not only replicated previously reported sound-evoked CAP amplitude depression 30-min after MPTP, but also confirmed the decrease in CAP was stable at the conclusion of the AN recording period (6-8 hours later). The effects of MPTP were stable within the recording period; CAP amplitude did not recover or show further decline during that window. Changes in spontaneous activity, which were the primary outcome of interest, accompanied changes in sound-evoked CAP potentials.

In one subject in which RWN was measured as an overall measure of ensemble neural activity, RWN was suppressed after MPTP (Figure 1). The primary study outcome was SR for individual AN fibers; SR was recorded from 261 ANFs from 15 control ears and 107 ANFs from three MPTP-treated ears (beginning 45 min after MPTP application) (see Figure 2). There were more high-SR AN fibers in controls (2A) than after MPTP (2B). Given unequal sample sizes, data were normalized as percent of total fibers per group (2C, 2D). The percent of fibers with the highest-SRs was decreased by MPTP.

Because there appeared to be a greater proportion of fibers in the 20-60 spikes/sec range, fibers were subdivided, first using the classical definition of low-SR as less than 0.5 spikes/sec and medium-SR as a rate between $0.5-18$ spikes/sec [following 20]. Then, the 
high-SR fibers with rates greater than 18 spikes/sec were further subdivided. After MPTP, there is a smaller proportion of fibers with rates greater than 80 spikes/sec and a greater proportion of fibers with rates in the 18-40 and 40-60 spikes/sec groupings (2E). MPTP did not increase the percentage of low-SR fibers and there was only a small increase in the medium-SR group. Statistical analysis revealed the distribution of SRs in control and MPTP-treated ears is significantly different (Chi-square $=23.28 ; \mathrm{df}=8, \mathrm{p}<.003)$.

The progression of differences (on the ordinal scale) between the fiber populations was also analyzed. First, the 0-0.5 and 0.5-18 bins were lumped together (as all other intervals had widths of $20 \mathrm{spikes} / \mathrm{sec}$ ). Since neurons cannot have negative firing rates, the distribution of values in the initial bin is subject to a floor effect and could be severely skewed; therefore, data in the first $(0-18 \mathrm{spike} / \mathrm{sec})$ bin were omitted. Data in the last bin (140-160 spikes/sec) were also omitted, as none of the AN fibers had rates of 140 spikes/sec or greater after MPTP. Across the 6 remaining firing rate bins, there was a perfect progression from largest difference in favor of the MPTP fibers (-.109) to largest difference in favor of the control fibers (+.071). This follows the hypergeometric distribution and has a probability of chance occurrence of $<.001389$. Therefore, the two distributions are reliably different and the progression of differences across SRs is not random. The SR-distribution after MPTP contains more fibers at the low end of the high-SR category and fewer at the high end of the category than does the normal SR-distribution.

\section{Discussion}

Extending previously reported decreases in sound-evoked AN activity in guinea pigs after application of 50-mM MPTP to the RWM [15], here, we report MPTP applied to the RWM depressed spontaneous AN activity in guinea pigs. When ensemble spontaneous activity was measured, RWN was suppressed 30- and 60-min after MPTP, and when single-unit SR was systematically assessed, there was a smaller percentage of fibers with rates in excess of 80 spikes/sec and a greater percentage of fibers with rates in the 18-40 and 40-60 spike/sec after MPTP. Statistical analysis confirmed the SR-distribution after MPTP contained more fibers at the low end of the high-SR category and fewer at the high end of the category compared to SR-distribution from controls. MPTP likely shifted the highest firing rates (>80 spikes/ sec) down to lower ranges (18-60 spikes/sec) within the high-SR category. However, the current results do not distinguish whether fibers with rates greater than $80 \mathrm{spikes} / \mathrm{sec}$ disappeared, or shifted their responses downwards into the 18-60 spikes/sec range.

The pattern of change in low-SR fibers observed here after MPTP contrasts with that reported following LOC and MOC transection in cat [21, 48] and chinchilla [50]. We detected no change in the proportion of low-SR $(<5$ spikes/sec) fibers, whereas others report an increase in the proportion of low-SR fibers. Liberman [21] proposed lesions turned high rates to medium rates and medium rates to low rates. Differences in effects on fibers with the lowest SR's may be explained by species differences, or procedural differences (knifecut lesions disrupting both LOC and MOC efferents vs MPTP). The recordings were also obtained under different anesthetic regimens, and at different post-lesion survival periods. New data from Liberman, et al. [24] clearly show the results of selective LOC lesions on sound-evoked AN activity increase with age in mice, thus long-term post-lesion survival 
may have an important effect on outcomes. Perhaps even more important, however, MPTP lesions are limited to the subpopulation of LOC fibers that contain DA [for discussion and reviews, see $1,7,12,18,34]$. The most parsimonious interpretation of the current data is that the observed shift in AN spontaneous activity after LOC disruption was produced by disrupting an otherwise tonic release of excitatory transmitter substances from a subset of the LOC terminals.

Because MPTP disrupts dopaminergic neurons, we interpret the observed changes in SR to reflect functional consequences of disruption of DA, or disruption of a neurotransmitter that is co-localized with DA. Because the SR was decreased, the effects suggest loss of a tonic excitatory substance. The data from Garrett et al. [9] on the effects of DA agonists and antagonists directly address the possibility that DA mediates AN activity, with different effects for agents that act at different receptor sub-types. Relevant to the current data, Garrett et al. [9] concluded that tonic endogenous DA release saturates $\mathrm{D}_{2}$ receptors, and that this endogenous DA has a tonic excitatory effort on AN activity mediated specifically at $\mathrm{D}_{2}$ receptors. The use of MPTP to lesion LOC neurons that contain DA should reduce any tonic DA release; observed decreases in SR and RWN are consistent with disruption of tonic neural excitation mediated by endogenous DA acting at $\mathrm{D}_{2}$ receptors as described by Garrett et al. [9].

The question as to whether changes in other transmitters, co-localized with DA, contributed to the observed effect must be considered. The data from Safieddine et al. [37] show cocontainment of DA with ACh and CGRP in guinea pig LOC efferent processes, which suggests likely co-disruption of DA, ACh, and CGRP after MPTP. Our preliminary triplelabeling of neurons in the guinea pig cochlea similarly revealed that DA is co-contained with ACh and CGRP, although there were also CGRP/ACh fibers that did not contain DA (unpublished results). CGRP also appears to exert a net excitatory tone with lower CAP thresholds, increased CAP amplitudes, and increased RWN amplitudes during chronic CGRP infusion in the guinea pig [13], and an observed depression of ABR wave I amplitudes in aCGRP-null mice [27]. Taken together, tonic loss of either DA or CGRP from DA-positive LOC neurons may provide a mechanistic explanation for decreased SR after MPTP application to the guinea pig cochlea.

The low-SR fibers, by virtue of higher thresholds and broader rate-level functions, effectively extend the dynamic range of the auditory periphery. Although high-SR fibers are more abundant [20], medium-SR and low-SR fibers are probably more important for transmitting information at high sound levels $[47,49]$. The LOC neurons are anatomically positioned to modulate AN activity. The current data, documenting for the first time that there are changes in SR after selective LOC disruption, add to the existing literature on changes in sound-evoked potentials after LOC disruption. Recordings from individual AN fibers in mice are possible [44], and it would be interesting to assess effects of LOC disruption on SR in mice, given the differences in observed effects on sound-evoked responses. DA is not present in cell bodies and peripheral terminals of LOC efferents that contain ACh and CGRP in the mouse [4], suggesting potentially important differences in LOC structure and function across species. 


\section{Acknowledgments}

Financial support for this study was provided by NIH-NIDCD grants, including R03-DC007342, P01-DC00078, R01-DC004194, R01-DC008131, and P30-DC05188. We thank J. McLaren, B. Hand, K. Halsey, S. Shubert, and $\mathrm{N}$. Wys, for their invaluable help and assistance.

\section{References}

1. Bledsoe, SC., Jr; Bobbin, RP.; Puel, JL. Neurotransmission in the inner ear. In: Jahn, AF.; SantosSacchi, J., editors. Physiology of the Ear. Raven Press; New York: 1988. p. 385-406.

2. Darrow KN, Maison SF, Liberman MC. Cochlear efferent feedback balances interaural sensitivity. Nat Neurosci. 2006; 9:1474-1476. [PubMed: 17115038]

3. Darrow KN, Maison SF, Liberman MC. Selective removal of lateral olivocochlear efferents increases vulnerability to acute acoustic injury. J Neurophysiol. 2007; 97:1775-1785. [PubMed: 17093118]

4. Darrow KN, Simons EJ, Dodds LW, Liberman MC. Dopaminergic innervation of the mouse inner ear: evidence for a separate cytochemical group of cochlear efferent fibers. J Comp Neurol. 2006; 498:403-414. [PubMed: 16871528]

5. Dolan DF, Nuttall AL, Avinash G. Asynchronous neural activity recorded from the round window. J Acoust Soc Am. 1990; 87:2621-2627. [PubMed: 2373796]

6. Evans EF. The frequency response and other properties of single fibres in the guinea-pig cochlear nerve. J Physiol. 1972; 226:263-287. [PubMed: 5083170]

7. Eybalin M. Neurotransmitters and neuromodulators of the mammalian cochlea. Physiol Rev. 1993; 73:309-373. [PubMed: 8097330]

8. Furman AC, Kujawa SG, Liberman MC. Noise-induced cochlear neuropathy is selective for fibers with low spontaneous rates. J Neurophysiol. 2013; 110:577-586. [PubMed: 23596328]

9. Garrett AR, Robertson D, Sellick PM, Mulders WH. The actions of dopamine receptors in the guinea pig cochlea. Audiol Neurootol. 2011; 16:145-157. [PubMed: 20668375]

10. Groff JA, Liberman MC. Modulation of cochlear afferent response by the lateral olivocochlear system: activation via electrical stimulation of the inferior colliculus. J Neurophysiol. 2003; 90:3178-3200. [PubMed: 14615429]

11. Irving S, Moore DR, Liberman MC, Sumner CJ. Olivocochlear efferent control in sound localization and experience-dependent learning. J Neurosci. 2011; 31:2493-2501. [PubMed: 21325517]

12. Le Prell, CG.; Bledsoe, SC., Jr; Bobbin, RP.; Puel, JL. Neurotransmission in the inner ear: Functional and molecular analyses. In: Jahn, AF.; Santos-Sacchi, J., editors. Physiology of the Ear. Singular Publishing; New York: 2001. p. 575-611.

13. Le Prell CG, Dolan D, Halsey K, Hughes LF. Chronic intra-cochlear delivery of CGRP, a lateral olivocochlear transmitter, enhances auditory nerve activity. Abs Assoc Res Otolaryngol. 2007; 30:120.

14. Le Prell CG, Dolan DF, Schacht J, Miller JM, Lomax MI, Altschuler RA. Pathways for protection from noise-induced hearing loss. Noise Health. 2003; 5:1-17. [PubMed: 14558888]

15. Le Prell CG, Halsey K, Hughes LF, Dolan DF, Bledsoe SC Jr. Disruption of lateral olivocochlear neurons via a dopaminergic neurotoxin depresses sound-evoked auditory nerve activity. J Assoc Res Otolaryngol. 2005; 6:48-62. [PubMed: 15735934]

16. Le Prell CG, Hughes LF, Bledsoe SC Jr. Dynorphin release by the lateral olivocochlear efferents may inhibit auditory nerve activity: a cochlear drug delivery study. Neurosci Lett. 2014 in press.

17. Le Prell CG, Shore SE, Hughes LF, Bledsoe SC Jr. Disruption of lateral efferent pathways: Functional changes in auditory evoked responses. J Assoc Res Otolaryngol. 2003; 4:276-290. [PubMed: 12943378]

18. Lendvai B, Halmos GB, Polony G, Kapocsi J, Horvath T, Aller M, Sylvester Vizi E, Zelles T. Chemical neuroprotection in the cochlea: the modulation of dopamine release from lateral olivocochlear efferents. Neurochem Int. 2011; 59:150-158. [PubMed: 21672572] 
19. Liberman LD, Wang H, Liberman MC. Opposing gradients of ribbon size and AMPA receptor expression underlie sensitivity differences among cochlear-nerve/hair-cell synapses. J Neurosci. 2011; 31:801-808. [PubMed: 21248103]

20. Liberman MC. Auditory-nerve response from cats raised in a low-noise chamber. J Acoust Soc Am. 1978; 63:442-455. [PubMed: 670542]

21. Liberman MC. Effects of chronic cochlear de-efferentation on auditory-nerve response. Hear Res. 1990; 49:209-223. [PubMed: 1705540]

22. Liberman MC. Efferent synapses in the inner hair cell area of the cat cochlea: an electron microscopic study of serial sections. Hear Res. 1980; 3:189-204. [PubMed: 7440423]

23. Liberman MC. Single-neuron labeling in the cat auditory nerve. Science. 1982; 216:1239-1241. [PubMed: 7079757]

24. Liberman MC, Liberman LD, Maison SF. Efferent feedback slows cochlear aging. J Neurosci. 2014; 34:4599-4607. [PubMed: 24672005]

25. Lin HW, Furman AC, Kujawa SG, Liberman MC. Primary neural degeneration in the guinea pig cochlea after reversible noise-induced threshold shift. J Assoc Res Otolaryngol. 2011; 12:605-616. [PubMed: 21688060]

26. Maison SF, Adams JC, Liberman MC. Olivocochlear innervation in the mouse: Immunocytochemical maps, crossed versus uncrossed contributions, and transmitter colocalization. J Comp Neurol. 2003; 455:406-416. [PubMed: 12483691]

27. Maison SF, Emeson RB, Adams JC, Luebke AE, Liberman MC. Loss of alpha CGRP reduces sound-evoked activity in the cochlear nerve. J Neurophysiol. 2003; 90:2941-2949. [PubMed: 12904337]

28. Maison SF, Liu XP, Eatock RA, Sibley DR, Grandy DK, Liberman MC. Dopaminergic signaling in the cochlea: receptor expression patterns and deletion phenotypes. J Neurosci. 2012; 32:344355. [PubMed: 22219295]

29. Maison SF, Liu XP, Vetter DE, Eatock RA, Nathanson NM, Wess J, Liberman MC. Muscarinic signaling in the cochlea: presynaptic and postsynaptic effects on efferent feedback and afferent excitability. J Neurosci. 2010; 30:6751-6762. [PubMed: 20463237]

30. Maison SF, Rosahl TW, Homanics GE, Liberman MC. Functional role of GABAergic innervation of the cochlea: phenotypic analysis of mice lacking $\operatorname{GABA}(\mathrm{A})$ receptor subunits alpha 1, alpha 2 , alpha 5, alpha 6, beta 2, beta 3, or delta. J Neurosci. 2006; 26:10315-10326. [PubMed: 17021187]

31. Nicklas WJ, Youngster SK, Kindt MV, Heikkila RE. MPTP, MPP+ and mitochondrial function. Life Sci. 1987; 40:721-729. [PubMed: 3100899]

32. Niu X, Bogdanovic N, Canlon B. The distribution and the modulation of tyrosine hydroxylase immunoreactivity in the lateral olivocochlear system of the guinea pig. Neuroscience. 2004; 125:725-733. [PubMed: 15099686]

33. Niu X, Canlon B. Activation of tyrosine hydroxylase in the lateral efferent terminals by sound conditioning. Hear Res. 2002; 174:124-132. [PubMed: 12433403]

34. Puel JL. Chemical synaptic transmission in the cochlea. Prog Neurobiol. 1995; 47:449-476. [PubMed: 8787031]

35. Ruel J, Nouvian R, Gervais d'Aldin C, Pujol R, Eybalin M, Puel JL. Dopamine inhibition of auditory nerve activity in the adult mammalian cochlea. Eur J Neurosci. 2001; 14:977-986. [PubMed: 11595036]

36. Safieddine S, Eybalin M. Triple immunoflourescence evidence for coexistence of acetylcholine, enkephalins, and calcitonin-gene related peptide within efferent (olivocochlear) neurons of rats and guinea pigs. Eur J Neurosci. 1992; 4:981-992. [PubMed: 12106433]

37. Safieddine S, Prior AM, Eybalin M. Choline acetyltransferase, glutamate decarboxylase, tyrosine hydroxylase, calcitonin gene-related peptide and opioid peptides coexist in lateral efferent neurons of rat and guinea-pig. Eur J Neurosci. 1997; 9:356-367. [PubMed: 9058055]

38. Satake M, Liberman MC. Morphological subclasses of lateral olivocochlear terminals? Ultrastructural analysis of inner spiral bundle in cat and guinea pig. J Comp Neurol. 1996; 371:621-632. [PubMed: 8841914]

39. Searchfield GD, Munoz DJ, Thorne PR. Ensemble spontaneous activity in the guinea-pig cochlear nerve. Hear Res. 2004; 192:23-35. [PubMed: 15157960] 
40. Sobkowicz HM, Slapnick SM. The efferents interconnecting auditory inner hair cells. Hear Res. 1994; 75:81-92. [PubMed: 8071157]

41. Sobkowicz HM, Slapnick SM, Nitecka LM, August BK. Compound synapses within the GABAergic innervation of the auditory inner hair cells in the adolescent mouse. J Comp Neurol. 1997; 377:423-442. [PubMed: 8989656]

42. Spoendlin H. Innervation densities of the cochlea. Acta Otolaryngol (Stockh). 1972; 73:235-248. [PubMed: 5015157]

43. Stephans SE, Miller GW, Levey AI, Greenamyre JT. Acute mitochondrial and chronic toxicological effects of 1-methyl-4-phenylpyridinium in human neuroblastoma cells. Neurotoxicology. 2002; 23:569-580. [PubMed: 12428729]

44. Taberner AM, Liberman MC. Response properties of single auditory nerve fibers in the mouse. $\mathbf{J}$ Neurophysiol. 2005; 93:557-569. [PubMed: 15456804]

45. Taranda J, Maison SF, Ballestero JA, Katz E, Savino J, Vetter DE, Boulter J, Liberman MC, Fuchs $\mathrm{PA}$, Elgoyhen AB. A point mutation in the hair cell nicotinic cholinergic receptor prolongs cochlear inhibition and enhances noise protection. PLoS Biol. 2009; 7:e18. [PubMed: 19166271]

46. Tsuji J, Liberman MC. Intracellular labeling of auditory nerve fibers in guinea pig: central and peripheral projections. J Comp Neurol. 1997; 381:188-202. [PubMed: 9130668]

47. Viemeister NF. Auditory intensity discrimination at high frequencies in the presence of noise. Science. 1983; 221:1206-1208. [PubMed: 6612337]

48. Walsh EJ, McGee J, McFadden SL, Liberman MC. Long-term effects of sectioning the olivocochlear bundle in neonatal cats. J Neurosci. 1998; 18:3859-3869. [PubMed: 9570815]

49. Young ED, Barta PE. Rate responses of auditory nerve fibers to tones in noise near masked threshold. J Acoust Soc Am. 1986; 79:426-442. [PubMed: 3950195]

50. Zheng XY, Henderson D, McFadden SL, Ding DL, Salvi RJ. Auditory nerve fiber responses following chronic cochlear de-efferentation. J Comp Neurol. 1999; 406:72-86. [PubMed: 10100893] 


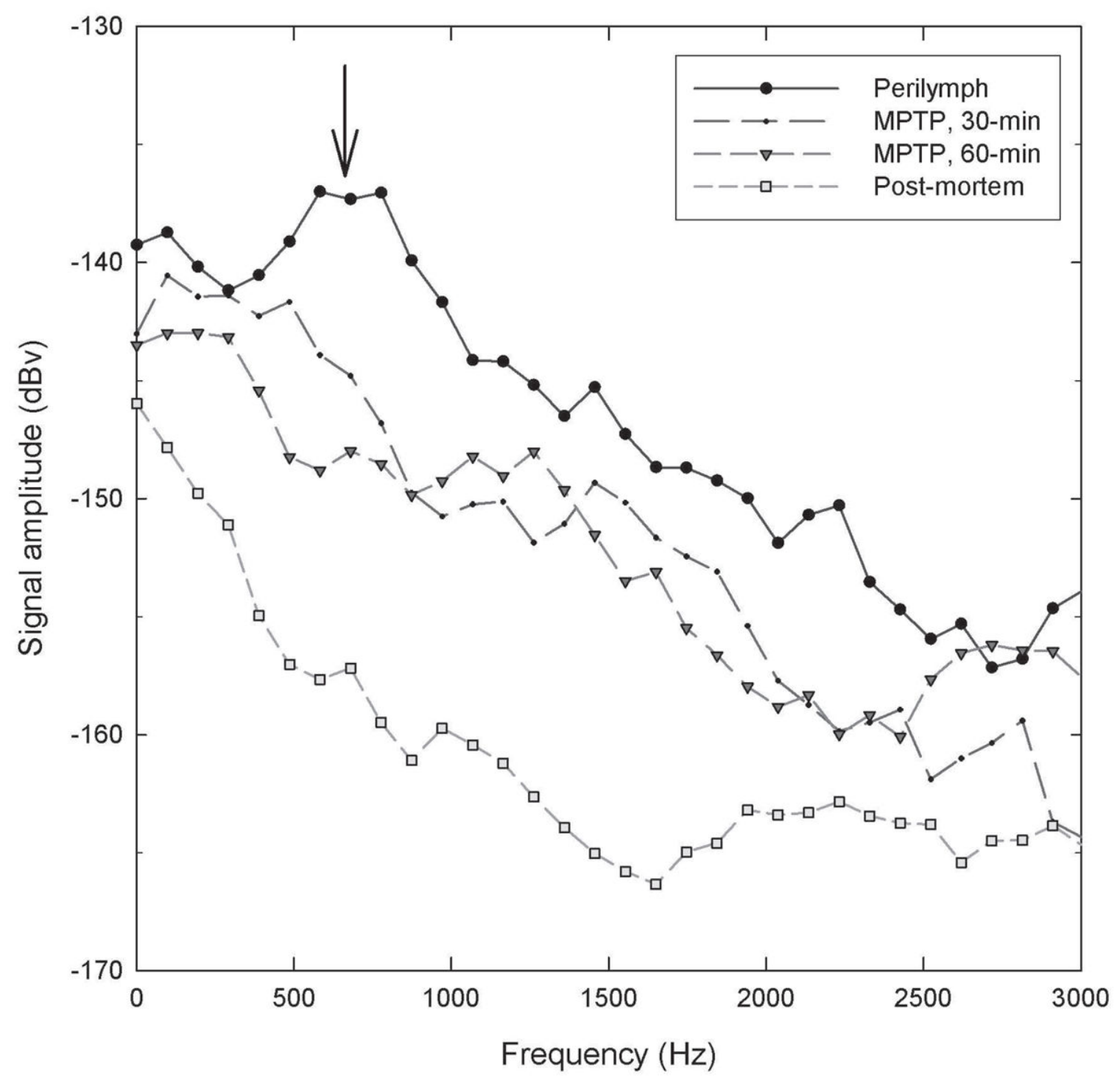

Figure 1.

MPTP decreases RW noise. Spectral waveforms were obtained 30-min after 6- $\mu$ l of artificial perilymph, 30- and 60-min after 6- $\mu$ l of 50-mM MPTP and post-mortem. The waveform obtained 30-min after AP (solid line) shows the characteristic broad peak in the $0.5-1.0 \mathrm{kHz}$ range (arrow). In the waveforms obtained 30- and 60-min post-MPTP, RWN waveform amplitude is diminished, with RWN waveform eliminated post-mortem. 

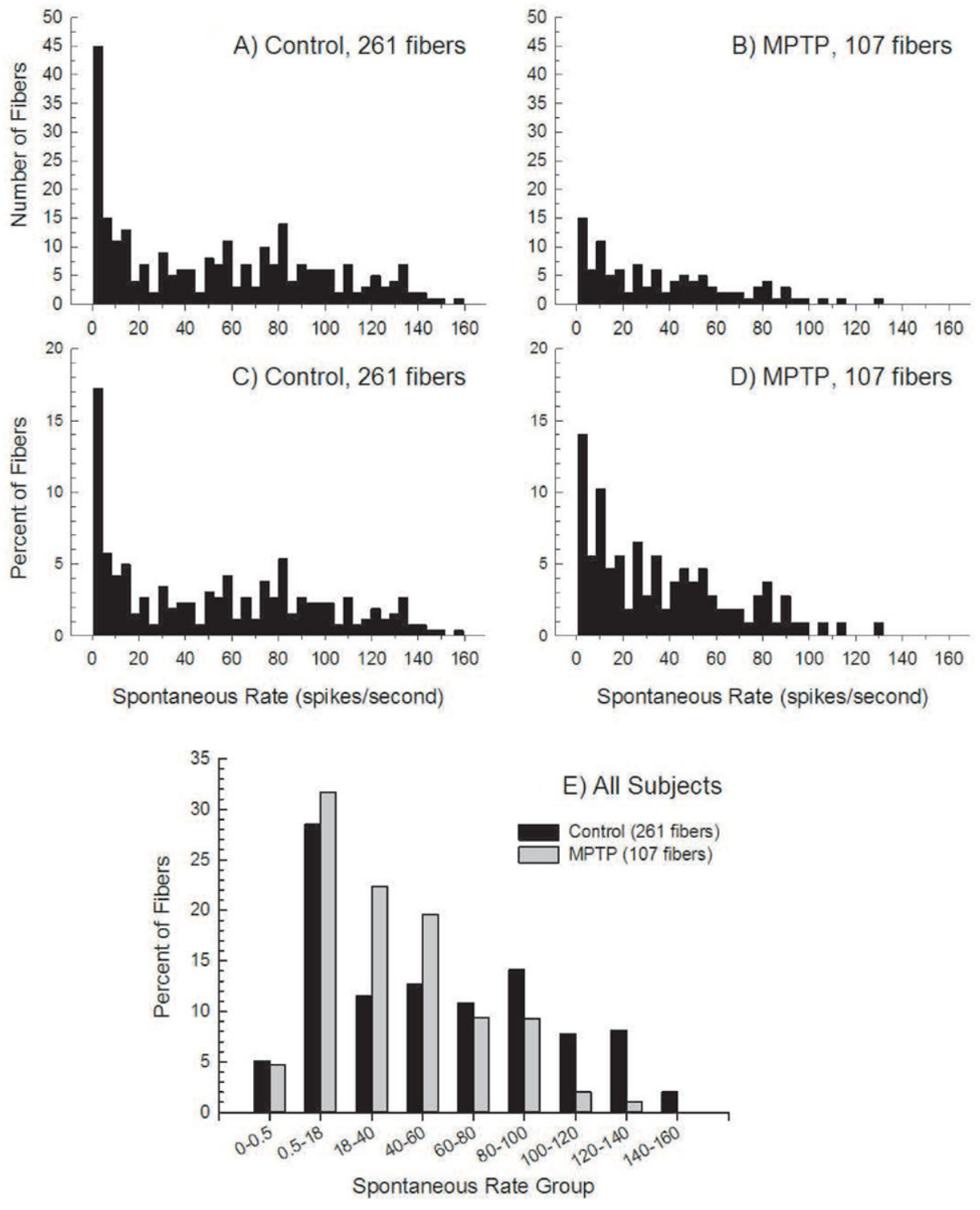

Figure 2.

Spontaneous activity recorded from single auditory nerve fibers in (2A) normal animals and (2B) MPTP lesioned animals. Due to unequal sample sizes, the same data are normalized as percentages (of the number of fibers within each group) in $2 \mathrm{C}$ and $2 \mathrm{D}$. In $2 \mathrm{E}$, spontaneous rate distributions for Control and MPTP-lesioned animals are shown. The data from panels $2 \mathrm{C}$ and $2 \mathrm{D}$ have been binned into the SR groups as indicated on the ordinate; the distributions are significantly different. 